\title{
Investigation of a unilateral pleural effusion in adults: British Thoracic Society pleural disease guideline 2010
}

\author{
Clare Hooper, ${ }^{1}$ Y C Gary Lee, ${ }^{2}$ Nick Maskell, ${ }^{3}$ on behalf of the BTS Pleural Guideline \\ Group
}

${ }^{1}$ Southmead Hospital, Bristol, UK

${ }^{2}$ Lung Institute of Western Australia, University Dept Med, Perth, Western Australia, Australia

${ }^{3}$ Department of Clinical Sciences, Southmead Hospital, University of Bristol, Bristol, UK

\section{Correspondence to} Nick Maskell, Academic Respiratory Unit, Department of Clinical Sciences, Southmead Hospital, University of Bristol, BS10 5NB;

nick.maskell@bristol.ac.uk

Received 12 February 2010 Accepted 4 March 2010

\section{INTRODUCTION}

Pleural effusions are a common medical problem with more than 50 recognised causes including disease local to the pleura or underlying lung, systemic conditions, organ dysfunction and drugs.

Pleural effusions occur as a result of increased fluid formation and/or reduced fluid resorption. The precise pathophysiology of fluid accumulation varies according to underlying aetiologies. As the differential diagnosis for a unilateral pleural effusion is wide, a systematic approach to investigation is necessary. The aim is to establish a diagnosis swiftly while minimising unnecessary invasive investigations and facilitating treatment, avoiding the need for repeated therapeutic aspirations when possible.

Since the 2003 guideline, several clinically relevant studies have been published, allowing new recommendations regarding image guidance of pleural procedures with clear benefits to patient comfort and safety, optimum pleural fluid sampling and processing and the particular value of thoracoscopic pleural biopsies. This guideline also includes a review of recent evidence for the use of new biomarkers including $\mathrm{N}$-terminal pro-brain natriuretic peptide (NT-proBNP), mesothelin and surrogate markers of tuberculous pleuritis.

\section{CLINICAL ASSESSMENT AND HISTORY}

- Aspiration should not be performed for bilateral effusions in a clinical setting strongly suggestive of a transudate unless there are atypical features or they fail to respond to therapy. $(\downarrow)$

- An accurate drug history should be taken during clinical assessment. $(\boldsymbol{})$

The history and physical examination of a patient with a pleural effusion may guide the clinician as to whether the effusion is a transudate or an exudate. This critical distinction narrows the differential diagnosis and directs further investigation.

Clinical assessment alone is often capable of identifying transudative effusions. Therefore, in an appropriate clinical setting such as left ventricular failure with a confirmatory chest $\mathrm{x}$-ray, such effusions do not need to be sampled unless there are atypical features or they fail to respond to treatment

Approximately $75 \%$ of patients with pulmonary embolism and pleural effusion have a history of pleuritic pain. These effusions tend to occupy less than one-third of the hemithorax and the dyspnoea is often out of proportion to the size of the effusion. $^{2{ }^{3}}$ As tests on the pleural fluid are unhelpful in diagnosing pulmonary embolism, a high index of suspicion is required to avoid missing the diagnosis.

The patient's drug history is also important. Although uncommon, a number of medications have been reported to cause exudative pleural effusions (box 1). Useful resources for more detailed information include the British National Formulary and the web site http://www.pneumotox.com/.

An occupational history including details about known or suspected asbestos exposure and potential secondary exposure via parents or spouses should be documented. An algorithm for the iinvestigation of a unilateral pleural effusion is shown in figure 1.

\section{INITIAL DIAGNOSTIC IMAGING \\ Plain radiography}

- Posteroanterior (PA) chest x-rays should be performed in the assessment of suspected pleural effusion. $(\boldsymbol{L})$

The plain chest radiographic features of pleural effusion are usually characteristic. The posteroanterior (PA) chest $\mathrm{x}$-ray is abnormal in the presence of about $200 \mathrm{ml}$ of pleural fluid. However, only $50 \mathrm{ml}$ of pleural fluid can produce detectable posterior costophrenic angle blunting on a lateral chest X-ray. ${ }^{4}$

In the intensive care setting, most chest $\mathrm{x}$-rays are performed as AP supine examinations, resulting in free pleural fluid lying posteriorly in the dependent portion of the chest. Consequently, effusions are seen as an increase in hemithorax opacity with preserved vascular shadows on the supine $\mathrm{x}$-ray. Other signs include the loss of the sharp silhouette of the ipsilateral hemidiaphragm and fluid tracking

Box 1 Commonly prescribed drugs known to cause pleural effusions (over 100 cases reported globally)

Methotrexate

- Amiodarone

- Phenytoin

- Nitrofurantoin

- $\beta$-blockers

Source: http://www.pneumotox.com (2009) 
Figure 1 Diagnostic algorithm for the investigation of a unilateral pleural effusion.

\section{Diagnostic algorithm for the investigation of a unilateral pleural effusion}

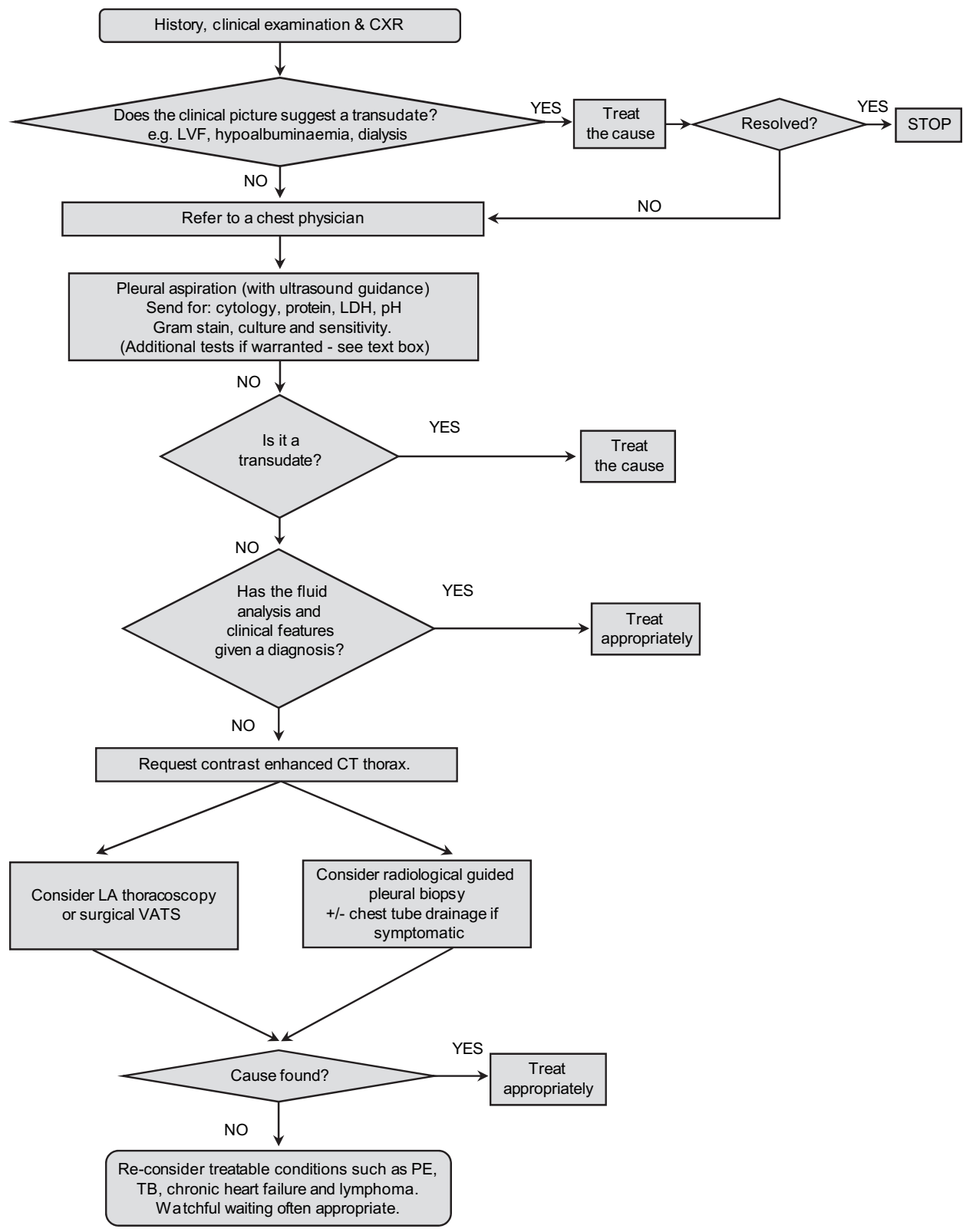

down into the oblique or horizontal fissures resulting in apparent fissural thickening. The volume of pleural fluid is commonly underestimated on a supine chest x-ray and 'normal' appearances do not exclude the presence of an effusion. ${ }^{5}$

Subpulmonic effusions occur when pleural fluid accumulates between the diaphragmatic surface of the lung and the diaphragm. They are often transudates, can be difficult to diagnose on the PA film and may require an ultrasound scan. The PA film will often show a lateral peaking of an apparently raised hemidiaphragm which has a steep lateral slope with a gradual medial slope (see figure 2). The lateral x-ray may have a flat appearance of the posterior aspect of the hemidiaphragm with a steep downward slope at the major fissure. ${ }^{6}$

\section{Ultrasound}

- Bedside ultrasound guidance significantly increases the likelihood of successful pleural fluid aspiration and reduces the risk of organ puncture. (B)
- Ultrasound detects pleural fluid septations with greater sensitivity than CT. (C)

Ultrasound guidance improves the rate of successful pleural aspiration. Several studies have shown that fluid can be successfully obtained using ultrasound in up to $88 \%$ of patients after a failed clinical and plain chest x-ray-guided attempt. ${ }^{7-9}$

Ultrasound guidance reduces the incidence of iatrogenic pneumothorax following thoracentesis and several studies have shown this effect to be independent of the size of the effusion. ${ }^{10} 11$ This benefit appears to be lost when the ' $\mathrm{X}$ marks the spot' method is employed, presumably due to differences in patient positioning between the ultrasound and the procedure. ${ }^{12}$

Clinical judgement with review of the chest x-ray was compared with ultrasonography in planning the diagnostic aspiration site in a prospective study including 255 clinician assessments of 67 patients. ${ }^{4}$ The sensitivity and specificity of clinical judgement compared with the gold standard of ultrasound was $76.6 \%$ and $60.3 \%$, respectively. Ultrasound increased 


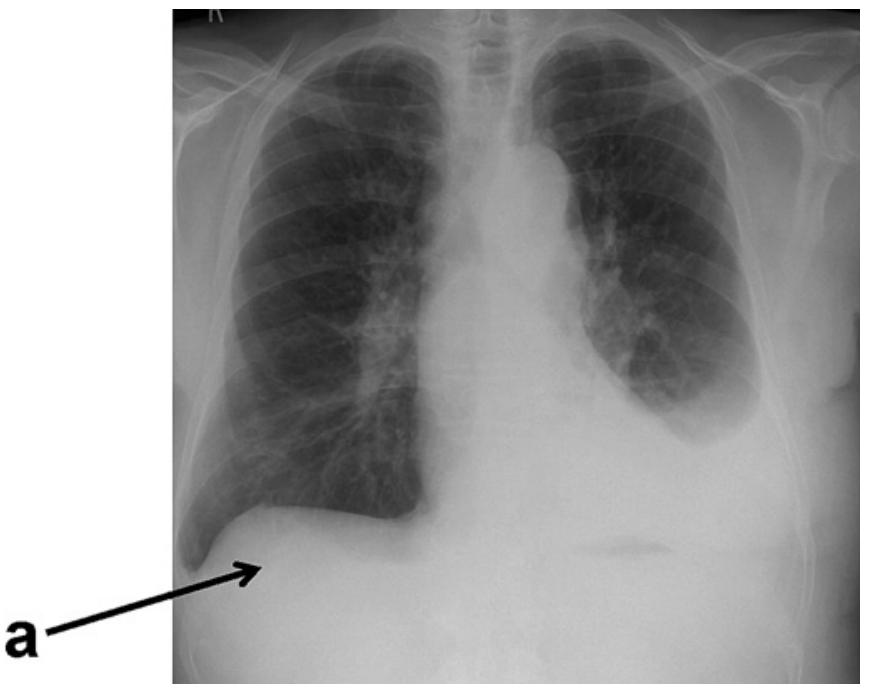

Figure 2 Chest x-ray showing a moderate left pleural effusion and subpulmonic effusion on the right (a). Note the lateral peaking of the right hemidiaphragm. Reproduced with permission from Professor David Milne, Auckland University.

the number of accurate sites by $26 \%$; $15 \%$ of clinically determined sites would have resulted in the puncture of liver, spleen or lung and, although there was increasing risk with small or loculated effusions, $60 \%$ of potential organ punctures occurred in radiologically large or moderate effusions.

Ultrasound is superior to plain radiography in diagnosing and quantifying pleural effusions and distinguishes pleural fluid from thickening with high specificity, particularly when colour Doppler is employed. ${ }^{13-16}$ It is particularly useful in the diagnosis of small effusions or in recumbent patients (eg, ventilated and critically ill) due to the low sensitivity of plain radiography in these situations.

The diagnostic role of thoracic ultrasound in the early investigation of pleural effusions extends beyond the identification and safe aspiration of fluid.

Ultrasound detects septations within pleural fluid with greater sensitivity than CT scanning. ${ }^{17}$ A septated appearance may be observed in malignant effusions or pleural infection and occurs with similar frequency in the two diagnoses. ${ }^{18}$

Ultrasound positively identifies exudative effusions when pleural fluid is complex, septated or echogenic, although simple (anechoic) effusions can be exudates or transudates. ${ }^{19}$

Ultrasound features can distinguish malignant from benign effusions. Qureshi et al demonstrated 95\% specificity for a malignant diagnosis, 95\% for parietal pleural thickening $>1 \mathrm{~cm}, 100 \%$ for visceral pleural thickening, 95\% for diaphragmatic thickening $>7 \mathrm{~mm}$ and $100 \%$ for diaphragmatic nodules as visualised on ultrasound examination. ${ }^{20}$ Overall sensitivity of ultrasound in the differentiation of malignant from benign effusions was $79 \%$ (95\% CI 61\% to $91 \%$ ) and specificity of $100 \%$ (95\% CI $82 \%$ to $100 \%$ ), with specificity comparing favourably with CT scanning (89\%).

\section{PLEURAL ASPIRATION}

- A diagnostic pleural fluid sample should be aspirated with a fine-bore (21G) needle and a $50 \mathrm{ml}$ syringe. $(\mathscr{})$

- Bedside ultrasound guidance improves the success rate and reduces complications (including pneumothorax) and is therefore recommended for diagnostic aspirations. (B)

- Pleural fluid should always be sent for protein, lactate dehydrogenase, Gram stain, cytology and microbiological culture. (C)

This is the primary means of evaluating pleural fluid and its findings are used to guide further investigation.

Pleural ultrasound should be used at the bedside to select a pleural aspiration site with safety. Ultrasound increases the chances of successful aspiration and minimises the need for repeated attempts. ${ }^{21}$ Direct ultrasound-guided aspiration or ultrasound at the bedside immediately before the procedure is preferable to the 'X marks the spot' approach. A lateral site is preferred, provided that adequate fluid is demonstrated here on ultrasound as the risk of intercostal vessel trauma increases with more posterior or medial punctures (see figure 3)

Patient consent and further technical details of pleural aspiration are covered in the guideline on pleural procedures. Table 1 shows sample collection guidance for specific pleural fluid tests.

A green needle $(21 \mathrm{G}$ ) and $50 \mathrm{ml}$ syringe are adequate for diagnostic pleural aspirations. If there is diagnostic suspicion of pleural infection and a pleural fluid $\mathrm{pH}$ is to be measured, aspirated fluid should immediately be drawn into a heparinised blood gas syringe which should then be capped while awaiting analysis to avoid exposure of the fluid to the air. The remaining sample should be divided between sample pots for microbiological ( $5 \mathrm{ml}$ ), biochemical $(2-5 \mathrm{ml})$ and cytological (remaining sample which should be 20-40 ml) analysis. Microscopic examination of Gramstained pleural fluid sediment is necessary for all pleural fluid samples. If infection is suspected, some of the pleural fluid should be sent in blood culture bottles which increases diagnostic accuracy, particularly for anaerobic organisms. ${ }^{22}$
Figure 3 CT scan $(A)$ before and $(B)$ 2 days later after a pleural aspiration with inappropriate medial approach and intercostal artery puncture with resultant haemothorax requiring surgical intervention. Note the active bleeding indicated by the arrow.
A

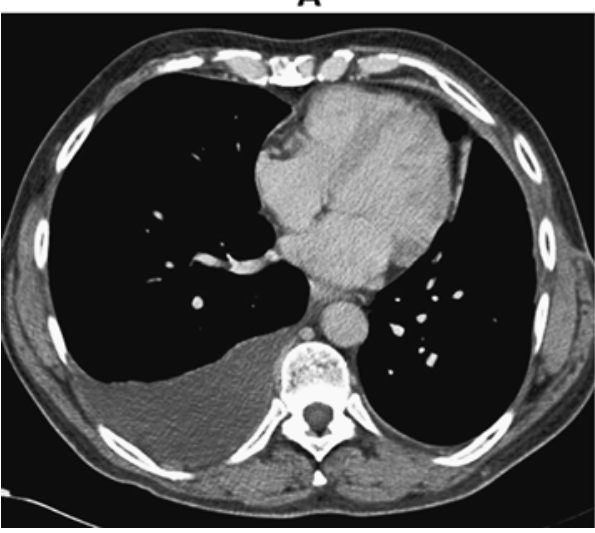

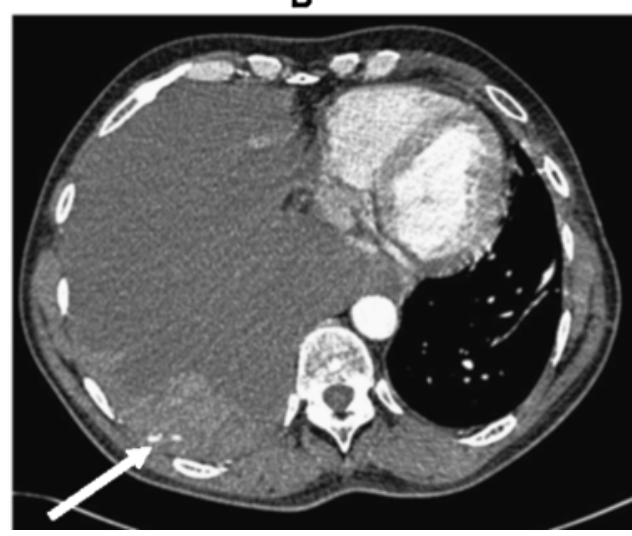


Table 1 Pleural fluid tests and sample collection guidance

Test Notes

Recommended tests for all sampled pleural effusions

Biochemistry: LDH and protein

$2-5 \mathrm{ml}$ in plain container or serum blood collection tube depending on local policy. Blood should be sent simultaneously to biochemistry for total protein and LDH so that Light's criteria can be applied

Microscopy and culture (MC and S)

$5 \mathrm{ml}$ in plain container. If pleural infection is particularly suspected, a further $5 \mathrm{ml}$ in both anaerobic and aerobic blood culture bottles should be sent

Cytological examination and differentia cell count

Maximum volume from remaining available sample in a plain universa container. Refrigerate if delay in processing anticipated (eg, out of hours)

Other tests sent only in selected cases as described in the text $\mathrm{pH}$

In non-purulent effusions when pleural infection is suspected. $0.5-1 \mathrm{ml}$ drawn up into a heparinised blood gas syringe immediately after aspiration. The syringe should be capped to avoid exposure to air. Processed using a ward arterial blood gas machine

Glucose

Occasionally useful in diagnosis of rheumatoid effusion. $1-2 \mathrm{ml}$ in fluoride oxalate tube sent to biochemistry

Acid-fast bacilli and TB culture

When there is clinical suspicion of TB pleuritis. Request with $\mathrm{MC}$ and $\mathrm{S} .5 \mathrm{ml}$ sample in plain container

Triglycerides and cholestero

To distinguish chylothorax from pseudochylothorax in milky effusions. Can usually be requested with routine biochemistry ( $\mathrm{LDH}$, protein) using the same sample

Amylase

Occasionally useful in suspected pancreatitis-related effusion. Can usually be requested with routine biochemistry

Haematocrit

Diagnosis of haemothorax. 1-2 m sample in EDTA container sent to haematology

$\mathrm{LDH}$, lactate dehydrogenase; $\mathrm{PH}$, pulmonary hypertension; TB, tuberculosis

There is conflicting evidence regarding the optimum volume of pleural fluid for diagnosis of malignancy; sensitivity depends on the cellularity of the sample and processing technique as well as volume submitted. ${ }^{23} 24$ It is sensible to send as large a volume as possible from the $50-60 \mathrm{ml}$ sample obtained following diagnostic aspiration as other tests only require small volumes. At room temperature the sample for cytology should be sent to the laboratory as quickly as possible but, if a delay is anticipated, the specimen can be refrigerated at $4^{\circ} \mathrm{C}$ for up to 14 days with no deterioration in the diagnostic yield for malignancy (table 1). ${ }^{25}$

\section{Appearance}

- The appearance of the pleural fluid and any odour should be recorded. $(\nu)$

- A pleural fluid haematocrit is helpful in the diagnosis of haemothorax. ( $レ$ )

Table 2 summarises the appearance of pleural effusions due to specific causes. Fluid may appear serous, blood-tinged, frankly

Table 2 Diagnostically useful pleural fluid characteristics

\begin{tabular}{ll}
\hline Fluid & Suspected disease \\
\hline Putrid odour & Anaerobic empyema \\
Food particles & Oesophageal rupture \\
Bile stained & Cholothorax (biliary fistula) \\
Milky & Chylothorax/pseudochylothorax \\
'Anchovy sauce' like fluid & Ruptured amoebic abscess \\
\hline
\end{tabular}

\section{Box 2 Light's criteria}

- Pleural fluid is an exudate if one or more of the following criteria are met:

- Pleural fluid protein divided by serum protein is $>0.5$

- Pleural fluid lactate dehydrogenase (LDH) divided by serum $\mathrm{LDH}$ is $>0.6$

- Pleural fluid LDH $>2 / 3$ the upper limits of laboratory normal value for serum $\mathrm{LDH}$.

bloody or purulent. Centrifuging turbid or milky pleural fluid will distinguish between empyema and lipid effusions. If the supernatant is clear, the turbid fluid was due to cell debris and empyema is likely while, if it is still turbid, chylothorax or pseudochylothorax are likely. ${ }^{26}$ The unpleasant smell of anaerobic infection may guide antibiotic choices and the smell of ammonia suggests urinothorax.

Grossly bloody pleural fluid is usually due to malignancy, pulmonary embolus with infarction, trauma, benign asbestos pleural effusions or post-cardiac injury syndrome. ${ }^{27} 28$

A haemothorax can be distinguished from other blood-stained effusions by performing a haematocrit on the pleural fluid. A pleural fluid haematocrit $>50 \%$ of the patient's peripheral blood haematocrit is diagnostic of a haemothorax. ${ }^{29}$

Differentiating between a pleural fluid exudate and transudate

- Light's criteria should be used to distinguish between a pleural fluid exudate and transudate (box 2). (B)

- In order to apply Light's criteria, the total protein and lactate dehydrogenase (LDH) should be measured in both blood and pleural fluid. (B)

Categorisation of pleural effusions into transudates and exudates is an important early step in narrowing the differential diagnosis and directing subsequent investigations and management (see boxes 3 and 4).

Classically, pleural fluid protein $>30 \mathrm{~g} / 1$ has indicated an exudate and $<30 \mathrm{~g} / \mathrm{l}$ a transudate. This classification is not accurate when serum protein is abnormal or when the pleural fluid protein is close to $30 \mathrm{~g} / \mathrm{l}$ and, as this is very common, the application of Light's criteria is always recommended. ${ }^{30}$

A considerable number of other biochemical markers have been compared with Light's criteria but the latter, with a diagnostic

\section{Box 3 Causes of pleural transudates}

Very common causes

- Left ventricular failure

- Liver cirrhosis

Less common causes

- Hypoalbuminaemia

- Peritoneal dialysis

- Hypothyroidism

- Nephrotic syndrome

- Mitral stenosis

Rare causes

- Constrictive pericarditis

- Urinothorax

- Meigs' syndrome 


\section{Box 4 Causes of pleural exudates}

Common causes

- Malignancy

- Parapneumonic effusions

- Tuberculosis

Less common causes

- Pulmonary embolism

- Rheumatoid arthritis and other autoimmune pleuritis

- Benign asbestos effusion

- Pancreatitis

- Post-myocardial infarction

- Post-coronary artery bypass graft

Rare causes

- Yellow nail syndrome (and other lymphatic disorders eg, lymphangioleiomyomatosis)

- Drugs (see table 2)

- Fungal infections

accuracy of $93-96 \%$, remains a robust method. ${ }^{31} 32$ This discriminatory accuracy is unlikely to be surpassed as the 'gold standard' for comparison in clinical diagnosis which itself carries an error rate.

In congestive cardiac failure, diuretic therapy increases the concentration of protein, lactate dehydrogenase (LDH) and lipids in pleural fluid and, in this context, Light's criteria are recognised to misclassify a significant proportion of effusions as exudates. ${ }^{33} 34$

Although the use of continuous likelihood ratios rather than a dichotomous division of transudates versus exudates has been proposed, particularly to overcome loss of accuracy of Light's criteria when pleural protein and LDH levels are close to cut-off values, there is probably little value in this cumbersome statistical method beyond careful interpretation of test results in the light of clinical judgement. ${ }^{35}$

\section{N-terminal pro-brain natriuretic peptide (NT-proBNP)}

NT-proBNP is a sensitive marker of both systolic and diastolic cardiac failure. Levels in blood and pleural fluid correlate closely and measurement of both has been shown in several series to be effective in discriminating transudates associated with congestive heart failure from other transudative or exudative causes. ${ }^{36-39}$ The cut-off value of these studies, however, varied widely from 600 to $4000 \mathrm{pg} / \mathrm{ml}$ (with $1500 \mathrm{pg} / \mathrm{ml}$ being most commonly used), and most studies excluded patients with more than one possible aetiology for their effusion. NT-proBNP has been shown to correctly diagnose congestive heart failure as a cause of most effusions that have been misclassified as exudates by Light's criteria. Use of this test may therefore avoid repeated invasive investigations in patients where there is a strong clinical suspicion of cardiac failure. ${ }^{40-42}$ As results with pleural fluid and blood are comparable, applying the test to blood alone is sufficient (see evidence table A available on the BTS website at www.brit-thoracic.org.uk).

Evidence for the use of measuring BNP (also known as C-terminal BNP, the active peptide from which NT-proBNP is cleaved) is relatively scarce to date.

\section{Pleural fluid differential cell counts}

- Pleural fluid cell proportions are helpful in narrowing the differential diagnosis but none are diseasespecific. (C)
Box 5 Causes of lymphocytic pleural effusions (ie,

lymphocytes account for $>50 \%$ of nucleated cells)

- Malignancy (including metastatic adenocarcinoma and mesothelioma)

- Tuberculosis

- Lymphoma

- Cardiac failure

- Post-coronary artery bypass graft

- Rheumatoid effusion

- Chylothorax

- Uraemic pleuritis

- Sarcoidosis

- Yellow nail syndrome

- Any long-standing pleural effusion tends to become populated by lymphocytes. Pleural malignancy, cardiac failure and tuberculosis are common specific causes of lymphocyte-predominant effusions. (C)

If the pleural fluid differential cell count shows a predominant lymphocytosis ( $>50 \%$ cells are lymphocytes), the most likely diagnoses worldwide are malignancy and tuberculosis (TB). ${ }^{43}$ Cardiac failure is also a common cause of a lymphocytic effusion. Very high lymphocyte proportions (>80\%) occur most frequently in TB, lymphoma, chronic rheumatoid pleurisy, sarcoidosis and late post-coronary artery bypass grafting (CABG) effusions (see box 5). ${ }^{44}$

Neutrophil-predominant pleural effusions are associated with acute processes. They occur in parapneumonic effusions, pulmonary embolism, acute TB and benign asbestos pleural effusions. $^{28} 45$

Pleural effusions in which $\geq 10 \%$ of cells are eosinophils are defined as eosinophilic. ${ }^{46}$ The most common cause of pleural fluid eosinophilia is air or blood in the pleural space. ${ }^{47}$ Pleural eosinophilia is a relatively non-specific finding as it can occur in parapneumonic effusions, drug-induced pleurisy, benign asbestos pleural effusions, Churg-Strauss syndrome, lymphoma, pulmonary infarction and parasitic disease. ${ }^{48}{ }^{49}$ Malignancy is also a common cause; a malignant diagnosis was made in $37 \%$ of 60 eosinophilic effusions in one series. ${ }^{46}$

$\mathrm{pH}$

- In non-purulent effusions, when pleural infection is suspected, pleural fluid $\mathrm{pH}$ should be measured providing that appropriate collection technique can be observed and a blood gas analyser is available. (B)

- Inclusion of air or local anaesthetic in samples may significantly alter the $\mathrm{pH}$ results and should be avoided. (B)

- In a parapneumonic effusion, a $\mathrm{pH}$ of $<7.2$ indicates the need for tube drainage. (B)

Pleural fluid acidosis $(\mathrm{pH}<7.30)$ occurs in malignant effusions, complicated pleural infection, connective tissue diseases (particularly rheumatoid arthritis), tuberculous pleural effusions and oesophageal rupture and, in isolation, it does not distinguish between these causes. ${ }^{50}$

Pleural fluid acidosis reflects an increase in lactic acid and carbon dioxide production due to locally increased metabolic activity as well as a fall in hydrogen ion flux across abnormal pleural membranes. Increased consumption of glucose without replacement in the same conditions means that pleural fluid often has both a low $\mathrm{pH}$ and low glucose concentration. ${ }^{51}$ 
In malignant pleural effusions low $\mathrm{pH}$ has been associated with shorter survival, more extensive disease and a lower chance of successful pleurodesis. ${ }^{52}$ A meta-analysis including 417 patients with malignant pleural effusions found that a pleural $\mathrm{pH}<7.28$ was associated with a median survival of 2.5 months and a 3 -month survival of $38.9 \%$ ( $95 \%$ CI $31.1 \%$ to $46.8 \%$ ) compared with a median survival of 4.3 months and 3-month survival of $61.6 \%(95 \%$ CI $55.7 \%$ to $67.4 \%)$ if the $\mathrm{pH}$ was $>7.28 .^{53}$

In clinical practice, the most important use for pleural fluid $\mathrm{pH}$ is aiding the decision to treat pleural infection with tube drainage. A meta-analysis of studies examining pleural $\mathrm{pH}$ and the need for chest tube drainage or surgery in patients with a parapneumonic effusion found that a $\mathrm{pH}<7.2$ was the most specific discriminator of complicated pleural infection. ${ }^{54}$ This is covered in detail in the pleural infection guideline.

In loculated parapneumonic effusions, fluid $\mathrm{pH}$ has been shown to vary significantly between locules so that a $\mathrm{pH}>7.2$ in a patient with other clinical indicators of complicated pleural infection should be viewed with caution. ${ }^{55}$

The collection and analysis technique can have a clinically significant impact on pleural fluid $\mathrm{pH}$ results. A prospective study found that exposure of fluid to air in the syringe increased the measured pleural fluid $\mathrm{pH}$ by $\geq 0.05$ in $71 \%$ of samples and inclusion of $0.2 \mathrm{ml}$ local anaesthetic produced a mean reduction in $\mathrm{pH}$ of 0.15 (95\% CI 0.13 to 0.18$).{ }^{56}$ Pleural fluid should therefore be collected and transported without exposure to atmospheric air and local anaesthetic avoided for diagnostic aspirations where the $\mathrm{pH}$ will be used to guide management. Pleural $\mathrm{pH}$ does not change significantly if processing is delayed for up to an hour at room temperature. An arterial blood gas analyser should be used. ${ }^{57}$ In routine clinical practice it is often difficult to adhere to these collection requirements and, when they cannot be achieved, overall clinical assessment may be preferable to reliance on a suboptimal pleural fluid $\mathrm{pH}$ result.

\section{Glucose}

In the absence of pleural pathology, glucose diffuses freely across the pleural membrane and the pleural fluid glucose concentration is equivalent to blood. ${ }^{1}$

A low pleural fluid glucose level $(<3.4 \mathrm{mmol} / \mathrm{l})$ may be found in complicated parapneumonic effusions, empyema, rheumatoid pleuritis and pleural effusions associated with TB, malignancy and oesophageal rupture. ${ }^{1}$ The most common causes of a very low pleural fluid glucose level $(<1.6 \mathrm{mmol} / \mathrm{l})$ are rheumatoid arthritis and empyema. ${ }^{58} 59$

Although glucose is usually low in pleural infection and correlates with pleural fluid $\mathrm{pH}$ values, it is a significantly less accurate indicator for chest tube drainage than $\mathrm{pH}{ }^{54}$

When pleural fluid glucose is measured, the sample should be sent in a fluoride oxalate tube.

\section{Amylase}

- Routine measurements of pleural fluid amylase or its isoenzymes are not warranted. It can, however, be useful in suspected cases of oesophageal rupture or effusions associated with pancreatic diseases. (C)

Pleural fluid amylase levels are elevated if they are higher than the upper limit of normal for serum or the pleural fluid/serum ratio is $>1.0 .{ }^{60}$ This suggests acute pancreatitis, pancreatic pseudocyst, rupture of the oesophagus, ruptured ectopic pregnancy or pleural malignancy (especially adenocarcinoma). ${ }^{61} 62$
Approximately $10 \%$ of malignant effusions have raised pleural fluid amylase levels, ${ }^{63}$ although there is probably no role for pleural amylase estimation in the routine investigation of malignant effusions. ${ }^{64}$

Isoenzyme analysis can be useful but is not readily available in many laboratories. Elevation of salivary amylase suggests oesophageal rupture or malignancy. ${ }^{61} 62$ Pleural effusions associated with pancreatic disease usually contain pancreatic amylase. ${ }^{61}$ The incidence of pleural effusion with acute pancreatitis exceeds $50 \%$. Patients with acute pancreatitis and a pleural effusion tend to have more severe disease and a higher likelihood of subsequently developing a pseudocyst than those without effusions. ${ }^{65}$ If oesophageal rupture is entertained as a differential diagnosis, urgent more specific investigation by contrast radiography or endoscopy is indicated.

There are few data regarding the measurement of pleural fluid lipase, although case reports of pleural effusions secondary to pancreatitis have described its elevation alongside amylase. ${ }^{66}$

\section{CYTOLOGY}

- Malignant effusions can be diagnosed by pleural fluid cytology in about $60 \%$ of cases. (B)

- The yield from sending more than two specimens (taken on different occasions) is very low and should be avoided. (B)

- Immunocytochemistry should be used to differentiate between malignant cell types and can be very important in guiding oncological therapy. (C)

If malignancy is suspected, cytological examination of the pleural fluid is a quick and minimally invasive way to obtain a diagnosis. Series examining the diagnostic rate for malignancy of pleural cytology have reported a mean sensitivity of about $60 \%$ (range $40-87 \%$ ). ${ }^{67-70}$ The yield from sending more than two specimens of pleural fluid taken on different occasions is low. One study found a yield of $65 \%$ from the first specimen, a further $27 \%$ from the second specimen and only $5 \%$ from the third. ${ }^{70}$ The diagnostic yield for malignancy depends on sample preparation, the experience of the cytologist and on tumour type. The diagnostic rate is higher for adenocarcinoma than for mesothelioma, squamous cell carcinoma, lymphoma and sarcoma.

Swiderek et al found that submission of a $60 \mathrm{ml}$ pleural fluid sample produced a significantly better sensitivity for the diagnosis of malignancy than $10 \mathrm{ml}$, but previous studies have shown that sending volumes $>50 \mathrm{ml}$ did not improve the diagnostic yield. ${ }^{23} 24$ The evidence for sending large volumes of pleural fluid is not strong enough to justify the increased risk of complications associated with the use of a venflon and threeway tap for initial diagnostic aspiration. As much fluid as possible should be sent for cytology from the available diagnostic sample (likely to be $20-40 \mathrm{ml}$ ) and, when the initial result is negative but malignancy is suspected, the sending of a higher volume sample following a second aspiration should be considered. If the initial aspiration is both therapeutic and diagnostic, $\geq 60 \mathrm{ml}$ should be sent for cytological examination.

Pleural fluid should be sent in a plain container which allows the cellular portion to separate, forming a fibrinous 'clot' which may enmesh malignant cells. These can then undergo histological examination and are reported with the fluid cytology. Some departments, however, prefer the use of bottles containing sodium citrate to keep the cells in free suspension. No other anticoagulants or preservatives should be used as they may interfere with cellular adherence to slides and immunocytochemistry. 
Table 3 Reporting of pleural fluid cytology results

\begin{tabular}{ll}
\hline Report & Interpretation \\
\hline Inadequate & $\begin{array}{l}\text { No mesothelial cells or only degenerate } \\
\text { cells present } \\
\text { No malignant cells seen } \\
\text { malignancy (does not exclude } \\
\text { malignancy) } \\
\text { May be of inflammatory or malignant } \\
\text { origin. Sending a further sample may be } \\
\text { helpful } \\
\text { Occasional cells with malignant features } \\
\text { buspicious for malignancy }\end{array}$ \\
Malignant & $\begin{array}{l}\text { Unequivocal malignant cells present } \\
\text { which require typing by } \\
\text { immunocytochemistry }\end{array}$ \\
\hline
\end{tabular}

The yield for malignancy increases if both cell blocks (which are formed by centrifuging the sample and extracting the solid cellular portion) and smears are prepared from pleural fluid samples. $^{71}$

Table 3 provides an interpretation of common pleural fluid cytology reports seen in clinical practice.

Once malignancy has been confirmed morphologically, immunocytochemistry should be used to differentiate between different malignant cell types. This can be performed on a cytology sample, cell block or a clot. ${ }^{72}$ There is particularly extensive morphological overlap between malignant mesothelioma and metastatic adenocarcinoma cells and immunocytochemistry can assist in their differentiation. However, whenever possible, pleural tissue should be obtained to confirm a diagnosis of malignant mesothelioma.

If lymphoma is suspected on morphological examination, ideally a sample should be submitted for flow cytometry for further typing, but immunocytochemistry can be used if this is unavailable (table 3). ${ }^{73}$

\section{TUMOUR MARKERS}

- Pleural fluid and serum tumour markers do not currently have a role in the routine investigation of pleural effusions. (C)

At a cut-off level that achieves $100 \%$ specificity for the diagnosis of malignancy, a panel of pleural fluid tumour markers including CEA, CA-125, CA 15-3 and CYFRA has been shown to reach a combined sensitivity of only $54 \%$, such that a negative result cannot be used to support a conservative approach to monitoring and investigation. ${ }^{74}$

Mesothelin, however, has been shown to have more promising diagnostic characteristics (see evidence table B available on the BTS website at www.brit-thoracic.org.uk).

\section{Mesothelin}

Mesothelin is a glycoprotein tumour marker that is present at higher mean concentrations in the blood and pleural fluid of patients with malignant mesothelioma than in patients with other causes of pleural effusion. ${ }^{75} 76$ Studies examining mesothelin levels in serum and/or pleural fluid have demonstrated a sensitivity of $48-84 \%$ and specificity of $70-100 \%$ for the diagnosis of mesothelioma. ${ }^{75-80}$ The negative predictive value of the test is limited by false negatives in sarcomatoid mesothelioma. ${ }^{79}$ Positive results have also been recognised in bronchogenic adenocarcinoma, metastatic pancreatic carcinoma, lymphoma and ovarian carcinoma. ${ }^{76} 7881$

A positive serum or pleural fluid mesothelin level is highly suggestive of pleural malignancy and might be used to expedite a tissue diagnosis, but a negative result cannot be considered reassuring. Pleural fluid mesothelin has been shown to have additional value beyond pleural fluid cytology in the diagnosis of mesothelioma and might be used for its positive predictive value to clarify indeterminate cytology results. ${ }^{80}$ Although mesothelin has a greater diagnostic accuracy than other tumour markers, its real clinical utility in the investigation of an undiagnosed pleural effusion, particularly in combination with routine clinical and radiological assessment, warrants further study before its use can be routinely recommended.

\section{FURTHER DIAGNOSTIC IMAGING}

Computed tomography (CT)

- CT scans for pleural effusion should be performed with contrast enhancement of the pleura and before complete drainage of pleural fluid. (C)

- CT scans should be performed in the investigation of all undiagnosed exudative pleural effusions and can be useful in distinguishing malignant from benign pleural thickening. (C)

- A CT scan should be requested for complicated pleural infection when initial tube drainage has been unsuccessful and surgery is to be considered. (C)

When investigating a pleural effusion, a contrast-enhanced thoracic CT scan should be performed before full drainage of the fluid as pleural abnormalities will be better visualised. ${ }^{82}$ Freeflowing pleural fluid is seen as a sickle-shaped opacity in the most dependent part of the thorax. Suspended air bubbles within the fluid imply septations (figure 4), but CT does not distinguish the internal characteristics of pleural fluid with the same sensitivity as ultrasound. ${ }^{17}$

CT is particularly helpful in the diagnosis of empyema when the pleura enhances intensely around the fluid which usually forms a lenticular opacity (figure 4). ${ }^{83}$ CT also distinguishes empyemas from lung abcesses.

There are features of contrast-enhanced thoracic CT scanning which can help differentiate between benign and malignant disease (figure 5). In a study of 74 patients, 39 of whom had malignant disease, Leung et al showed that malignant disease is favoured by nodular pleural thickening, mediastinal pleural thickening, parietal pleural thickening $>1 \mathrm{~cm}$ and circumferential pleural thickening. These features had specificities of $94 \%$, $94 \%, 88 \%$ and $100 \%$, respectively, and sensitivities of $51 \%, 36 \%$, $56 \%$ and $41 \% .{ }^{85}$ The accuracy of the criteria of Leung et al for the detection of pleural malignancy has been confirmed in several prospective studies. ${ }^{82} 86$ Differentiation of pleural mesothelioma

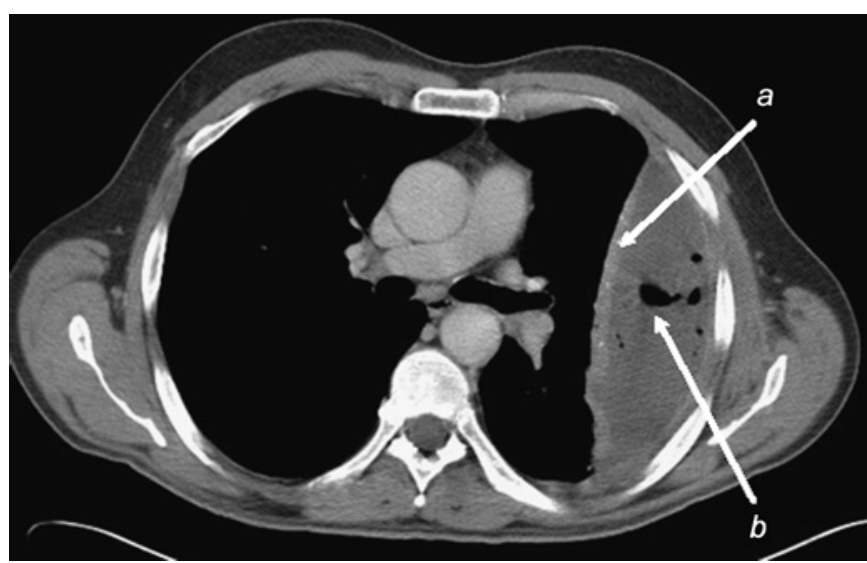

Figure 4 CT scan of left empyema with pleural enhancement (a) and suspended air bubbles (b). 


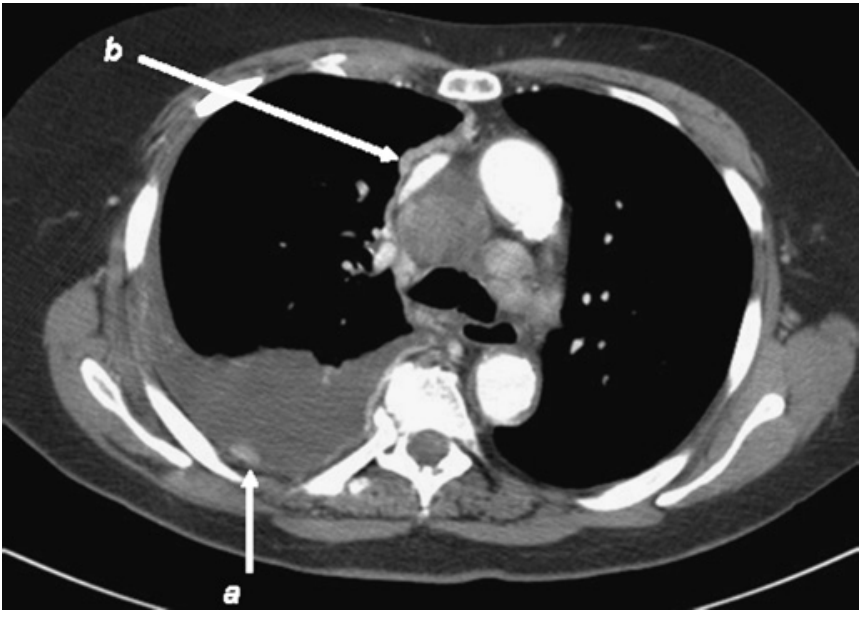

Figure 5 Right malignant pleural effusion with enhancing nodular pleural thickening (a) extending over the mediastinum (b).

from metastatic pleural malignancy is very difficult as the conditions share many CT features.

\section{Magnetic resonance imaging (MRI)}

MRI distinguishes accurately between benign and malignant pleural effusions via differences in signal intensity on T2-weighted images. ${ }^{87}$ Distinction of morphological features of pleural malignancy by MRI has been shown in some studies to equal CT and assessment of diaphragmatic and chest wall involvement is superior. ${ }^{88}$ Access to MRI is limited and it does not have a place in the routine investigation of pleural effusions at this time, but may be used to accurately assess pleural disease in patients for whom contrast is contraindicated. Dynamic contrast-enhanced MRI has shown promise in the monitoring of response of pleural mesothelioma to chemotherapy. ${ }^{89}$

\section{PET-CT imaging}

While the uptake of 18-fluorodeoxyglucose (FDG) has been shown to be greater in malignant pleural effusions, the value of PET-CT imaging in distinguishing benign and malignant disease is limited by false positives in patients with pleural inflammation including pleural infection and following talc pleurodesis. ${ }^{90-92}$ PET-CT imaging does not currently have a role in the routine investigation of pleural effusions but, in common with dynamic contrastenhanced MRI, there is emerging evidence suggesting a potential role in monitoring the response to treatment of pleural mesothelioma. ${ }^{93-95}$

\section{INVASIVE INVESTIGATIONS}

Percutaneous pleural biopsy

-When investigating an undiagnosed effusion where malignancy is suspected and areas of pleural nodularity are shown on contrast-enhanced CT, an image-guided cutting needle is the percutaneous pleural biopsy method of choice. (A)

- Abrams needle biopsies are only diagnostically useful in areas with a high incidence of TB, although thoracoscopic and image-guided cutting needles have been shown to have a higher diagnostic yield. (C)

A review of Abrams pleural biopsy yield from 2893 examinations showed a diagnostic rate of only $57 \%$ for malignancy. ${ }^{96}$ The yield over pleural fluid cytology alone is increased by only $7-27 \%$ for malignancy. ${ }^{68} 69$ Complications of Abrams pleural biopsy include site pain (1-15\%), pneumothorax (3-15\%), vasovagal reaction $(1-5 \%)$, haemothorax $(<2 \%)$, site haematoma $(<1 \%)$, transient fever $(<1 \%)$ and, very rarely, death secondary to haemorrhage.

The contrast-enhanced thoracic CT scan of a patient with a pleural effusion will often show a focal area of abnormal pleura. An image-guided cutting needle biopsy allows that focal area of abnormality to be biopsied. It has a higher yield than that of blind pleural biopsy in the diagnosis of malignancy. This technique is particularly useful in patients who are unsuitable for thoracoscopy.

Pleural malignant deposits tend to predominate close to the midline and diaphragm, which are areas best avoided when performing an Abrams biopsy. However, these anatomical regions are possible to biopsy safely under radiological imaging. In a recent prospective study, 33 patients with a pleural effusion and pleural thickening demonstrated on contrast-enhanced CT underwent percutaneous image-guided pleural biopsy. Correct histological diagnosis was made in 21 of 24 (sensitivity $88 \%$, specificity $100 \%$ ) including 13 of 14 patients with mesothelioma (sensitivity 93\%). ${ }^{97}$ In a larger retrospective review of imageguided pleural biopsy in one department by a single radiologist, 18 of the 21 mesothelioma cases were correctly identified (sensitivity $86 \%$, specificity $100 \%$ ). ${ }^{98}$

Image-guided cutting needle biopsies have been shown to be superior to Abrams needle biopsies in the diagnostic yield for malignant disease. In a randomised controlled trial of 50 consecutive patients with cytology-negative suspected malignant pleural effusions, Abrams biopsy correctly diagnosed malignancy in $8 / 17$ (sensitivity $47 \%$, specificity $100 \%$, negative predictive value $44 \%$, positive predictive value $100 \%$ ) and CTguided biopsy correctly diagnosed malignancy in 13/15 (sensitivity $87 \%$, specificity $100 \%$, negative predictive value $80 \%$, positive predictive value $100 \%) .{ }^{99}$

In a prospective trial comparing local anaesthetic thoracoscopy with Abrams biopsy in an area with a high prevalence of $\mathrm{TB},{ }^{100}$ thoracoscopy was found to have a combined culture/ histology sensitivity of $100 \%$ compared with $79 \%$ for Abrams pleural biopsy. The technique with the highest diagnostic rate for tuberculous pleuritis on the basis of published evidence is therefore local anaesthetic thoracoscopy. However, since blind pleural biopsy has reasonably high sensitivity and is likely to be more cost effective as an initial diagnostic procedure, it will often be the procedure of first choice in resource-poor areas with a high incidence of TB. Blind pleural biopsy cannot be justified for the diagnosis of TB where the incidence is not high enough to maintain operator experience (see evidence table $\mathrm{C}$ available on the BTS website at www.brit-thoracic.org.uk).

\section{Thoracoscopy}

- Thoracoscopy is the investigation of choice in exudative pleural effusions where a diagnostic pleural aspiration is inconclusive and malignancy is suspected. (C)

In patients with a symptomatic exudative pleural effusion where a diagnostic pleural aspiration is negative or inconclusive, thoracoscopy is suggested as the next choice investigation since the procedure will be relatively uncomplicated and pleurodesis is likely to be indicated.

\section{Local anaesthetic thoracoscopy}

Local anaesthetic thoracoscopy can be performed by physicians or surgeons and is a safe and well tolerated procedure. Major complications (eg, empyema, haemorrhage and pneumonia) occur in only $2.3 \%(95 \%$ CI $1.9 \%$ to $2.8 \%)$ and death is rare at 
$0.40 \%$ (95\% CI $0.2 \%$ to $0.7 \%$ ). It has a diagnostic sensitivity for malignant pleural disease of $92.6 \% \quad(95 \%$ CI $91.0 \%$ to $93.9 \%) .{ }^{101-121}$ It also has a higher diagnostic yield than blind pleural biopsy for tuberculous pleuritis. Talc poudrage can be administered at the end of the procedure which achieves a successful pleurodesis in $80-90 \%$ (see BTS guideline on thoracoscopy for further detail.

\section{Video-assisted thoracoscopic surgery (VATS)}

This is performed by thoracic surgeons and requires a general anaesthetic. It is therefore not a suitable option for frail individuals and those with other severe comorbidities. This procedure reports similarly high diagnostic sensitivity rates of approximately $95 \%$ for malignancy and is also relatively safe with a low complication rate. In one series of 566 examinations, the most common side effect was subcutaneous emphysema with cardiac dysrhythmia and air embolism occurring in $<1 \%$ and no deaths. ${ }^{122}$

One advantage of VATS over local anaesthetic thoracoscopy is that the surgical operator is able to proceed to other thoracic surgical options, if appropriate, at the time of the procedure. In particular, a judgement can be made as to whether the lung is trapped or free to expand. In trapped lung syndrome, pleurodesis is likely to be less effective so an indwelling pleural catheter can be placed at the time of VATS (see BTS guideline on thoracoscopy.

\section{Bronchoscopy}

- Routine diagnostic bronchoscopy should not be performed for undiagnosed pleural effusion. (C)

- Bronchoscopy should be considered if there is haemoptysis or clinical or radiographic features suggestive of bronchial obstruction. (C)

Bronchoscopy has a limited role in the investigation of patients with an undiagnosed pleural effusion as its diagnostic yield is very low. ${ }^{123-126}$ It should be reserved for patients whose radiology suggests the presence of a mass or loss of volume or when there is a history of haemoptysis, possible aspiration of a foreign body or a trapped lung with a suspicion of a proximal lung mass.

If bronchoscopy is deemed necessary, it should be performed after pleural drainage in order to perform adequate examination without extrinsic airway compression by pleural fluid.

\section{SPECIFIC CONDITIONS AND TESTS \\ Tuberculous pleurisy}

-When pleural biopsies are taken, they should be sent for both histological examination and culture to improve the diagnostic sensitivity for TB. (B)

- Thoracoscopic pleural biopsies are the test most likely to yield positive mycobacterial culture (and therefore drug sensitivity) results. (B)

- Surrogate markers of pleural TB are useful 'rule out' tests in low incidence countries. Adenosine deaminase is the most thoroughly validated to date. (B)

Tuberculous pleuritis is a type IV hypersensitivity reaction to mycobacterial protein and the mycobacterial load in the pleural fluid is usually low. Pleural fluid microscopy for acid-fast bacilli therefore has a sensitivity of $<5 \%$ and pleural fluid culture of $10-20 \%{ }^{127}$ Thoracoscopic pleural biopsy has been shown to have a sensitivity of $>70 \%$ for culture of pleural tissue and overall diagnostic sensitivity approaches $100 \%$ when evidence of caseating granulomas on pleural biopsy histology is combined with culture. ${ }^{100}$
Surrogate markers of pleural TB

Tuberculous pleuritis is a treatable cause of a lymphocytic pleural effusion. It is desirable to exclude the diagnosis in patients with lymphocytic effusions, avoiding inappropriate and side effect-prone empirical antituberculous therapy. In patients who are unfit for invasive investigations, pleural fluid or blood biomarkers of infection can be useful. Adenosine deaminase (ADA) is an enzyme present in lymphocytes, and its level in pleural fluid is significantly raised in most tuberculous pleural effusions. A meta-analysis of 63 studies on the diagnostic use of ADA confirmed a sensitivity of $92 \%$, specificity $90 \%$ and positive and negative likelihood ratios of 9.0 and 0.10 , respectively. ${ }^{128}$ Raised ADA levels can also be seen in empyema, rheumatoid pleurisy and, occasionally, in malignancy. Restricting the use of ADA to lymphocytic effusions or measurement of isoenzyme ADA-2 can reduce the false positives significantly. ${ }^{129} \mathrm{ADA}$ is very cheap and quick to perform and remains stable when stored at $4^{\circ} \mathrm{C}$ for up to 28 days. ${ }^{130}$ It is useful in patients with HIV or those immunosuppressed (eg, renal transplant). In countries with a low prevalence of $\mathrm{TB}, \mathrm{ADA}$ is a useful 'rule out' test.

Unstimulated interferon $\gamma$ levels in pleural fluid have also been shown to have similar diagnostic accuracy as ADA in a metaanalysis. ${ }^{131}$ The former, however, is more expensive. Interferon $\gamma$ release assays (IGRAs) have been studied. Applied to blood in areas with a low incidence of $\mathrm{TB}$, sensitivities as high as $90 \%$ have been reported but specificity is limited by an inability of the tests to distinguish latent from active TB. ${ }^{132}$ Small studies have applied IGRAs to pleural fluid with demonstration of superior sensitivities (96.4\%), although the commercial tests are not yet validated for fluids other than blood. ${ }^{133}$ While further studies are awaited, overall diagnostic performance, ease of use and cost are unlikely to rival that of $\mathrm{ADA} .^{134}$

In well-resourced healthcare settings, the greatest chance of obtaining mycobacterial culture and sensitivities should be pursued via thoracoscopic pleural biopsies. However, a large review of 7549 cases of tuberculous pleuritis by the Center for Disease Control showed that drug resistance patterns of pleural $\mathrm{TB}$ in the USA broadly reflected those of pulmonary $\mathrm{TB}$ in the same region. ${ }^{135}$ If mycobacterial culture and sensitivities are not achieved, the treatment regime should reflect that of the local resistance patterns.

\section{Connective tissue diseases}

Rheumatoid arthritis and systemic lupus erythematosus (SLE) are the most common connective tissue diseases to involve the pleura. Pleural effusions occur in connective tissue disease due to primary autoimmune pleuritis or secondary to renal, cardiac, thromboembolic disease or drug therapy.

Rheumatoid arthritis-associated pleural effusions

- Most chronic pleural effusions secondary to rheumatoid arthritis have a very low glucose level of $<1.6 \mathrm{mmol} / \mathrm{l}$ (29 mg/dl). (D)

Pleural involvement occurs in $5 \%$ of patients with rheumatoid arthritis. ${ }^{136}$ Rheumatoid arthritis-associated pleural effusions occur more frequently in men, although the disease itself is more common in women. ${ }^{137}$ Chronic rheumatoid effusions are the most common cause of pseudochylous (cholesterol) effusions in countries with a low incidence of TB, but they can also be serous or haemorrhagic in appearance. ${ }^{138} 139$ The measurement of triglycerides and cholesterol in milky effusions will confirm the diagnosis of a pseudochylous picture and, in the presence of 
rheumatoid arthritis, this makes other causes for the effusion unlikely. Rheumatoid arthritis is unlikely to be the cause of a chronic effusion if the glucose level in the fluid is $>1.6 \mathrm{mmol} / \mathrm{l}$, serving as a useful screening test. ${ }^{58} 80 \%$ of rheumatoid pleural effusions have a pleural fluid glucose to serum ratio of $<0.5$ and a $\mathrm{pH}<7.30{ }^{140}$ However, in acute rheumatoid pleurisy, the glucose and $\mathrm{pH}$ may be normal. ${ }^{141}$ Measurement of C4 complement in pleural fluid may be of additional help, with levels $<0.04 \mathrm{~g} / 1$ in all cases of rheumatoid pleural disease and in only 2 of 118 controls reported in one study. ${ }^{141}$ Rheumatoid factor can be measured on the pleural fluid and often has a titre of $>1: 320 .{ }^{142}$ However, it can be present in effusions of other aetiology and often mirrors the serum value, adding little diagnostically. $^{141}$

\section{Systemic lupus erythematosus (SLE)}

- Pleural fluid antinuclear antibodies should not be measured routinely as it reflects the serum level and is therefore usually unhelpful. (C)

Pleuritis is the first manifestation of SLE in $5-10 \%$ of patients but is an early feature in $25-30 \%$ and is usually accompanied by multisystem involvement. Pleural effusions are frequently small and are bilateral in $50 \%$ of patients. ${ }^{143}$

No test definitively positively distinguishes SLE pleuritis from other causes of exudative effusions. Biochemical features are not distinctive or consistent. ${ }^{144} 145$ Elevated pleural fluid antinuclear antibodies (ANA) and an increased pleural fluid to serum ANA ratio is suggestive of SLE pleuritis, but elevation is also sometimes seen in malignant effusions. ${ }^{146}$ Porcel et al measured pleural fluid ANA titres in 266 patients with pleural effusions of established cause including 15 with SLE pleuritis. They demonstrated a sensitivity of $100 \%(95 \%$ CI $97 \%$ to $100 \%)$ and a specificity of $94 \%$ (95\% CI $91 \%$ to $97 \%$ ) for the pleural fluid test but, consistent with previous reports, the results were identical when testing serum. ${ }^{147}$ There is no additional value in measuring pleural fluid ANA above the serum test.

\section{Pleural effusions due to pulmonary embolism}

Pleural effusions detectable on chest x-ray occur in $23-48 \%$ of patients with pulmonary emboli. ${ }^{148}$ Effusions are small (less than one-third of the hemithorax) in up to $90 \%$ of cases, although moderate and massive effusions are also recognised. ${ }^{3}$ They may be ipsilateral, contralateral or bilateral relative to the radiologically-detected embolus. ${ }^{2} 3$

Recent series applying Light's criteria have found that pleural effusions associated with pulmonary embolism are always exudates. ${ }^{3} 149$ Fluid characteristics, however, are non-specific and unhelpful in making the diagnosis which should be pursued radiologically, given a high index of clinical suspicion or in the context of an effusion that remains undiagnosed after standard baseline investigations.

\section{Chylothorax and pseudochylothorax}

- If a chylothorax or pseudochylothorax is suspected, pleural fluid should be tested for cholesterol crystals and chylomicrons and the pleural fluid triglyceride and cholesterol levels measured. (C)

If the pleural fluid appears milky, chylothorax and pseudochylothorax must be considered. Occasionally an empyema can be sufficiently turbid to be confused with chyle. They can be distinguished by bench centrifugation which leaves a clear supernatant in empyema while chylous effusion remains milky. It should be noted that, in starved patients, chyle may not appear milky.
Box 6 Common causes of chylothorax and pseudochylothorax

Chylothorax

- Trauma: thoracic surgery (especially if involving posterior mediastinum, eg oesophagectomy), thoracic injuries

- Neoplasm: lymphoma or metastatic carcinoma

- Miscellaneous: disorders of lymphatics (including lymphangioleiomyomatosis), tuberculosis, cirrhosis, obstruction of central veins, chyloascites

- Idiopathic (about 10\%)

Pseudochylothorax

- Tuberculosis

- Rheumatoid arthritis

True chylous effusions (chylothorax) result from disruption of the thoracic duct or its tributaries such that chyle is present in the pleural space.

Trauma, particularly following thoracic surgery, probably causes about $50 \%$ with medical causes including malignancy (particularly lymphoma), TB and lymphatic malformations accounting for most of the remaining half (box 6). ${ }^{150}$

Unlike other exudative effusions, the diagnosis of chylothorax or its underlying cause cannot usually be established from thoracoscopy or pleural biopsies. In non-surgical cases, a CT scan of the thorax to exclude mediastinal pathology (especially lymphoma) is mandatory. The site of leak may be demonstrated by lymphangiography.

Chylothorax must be distinguished from pseudochylothorax or 'cholesterol pleurisy' which results from the accumulation of cholesterol crystals. Rheumatoid pleurisy and tuberculous pleuritis are the most commonly reported causes of a pseudochylous effusion. ${ }^{138} 151$ Pseudochylothorax usually arises from chronic (often years) pleural effusion and the pleura is usually markedly thickened. ${ }^{152}$ Exceptions do exist and clinicians are encouraged not to discard the diagnosis in the absence of chronicity and thickened pleura. ${ }^{153}$

Chylothorax and pseudochylothorax can be discriminated by lipid analysis of the fluid. Demonstration of chylomicrons confirms a chylothorax, whereas the presence of cholesterol crystals diagnoses pseudochylothorax. A true chylothorax will usually have a high triglyceride level, usually $>1.24 \mathrm{mmol} / 1$ $(110 \mathrm{mg} / \mathrm{dl})$ and can usually be excluded if the triglyceride level is $<0.56 \mathrm{mmol} / 1(50 \mathrm{mg} / \mathrm{dl})$. In a pseudochylothorax a cholesterol level $>5.18 \mathrm{mmol} / 1(200 \mathrm{mg} / \mathrm{dl})$ or the presence of cholesterol crystals is diagnostic irrespective of triglyceride levels (see table 4). ${ }^{152-154}$

Chylothorax can be a result of transdiaphragmatic migration of chylous ascites, which can be secondary to hepatic cirrhosis In these cases, the pleural effusion is often a transudate.

Table 4 Pleural fluid lipid values in pseudochylothorax and cylothorax

\begin{tabular}{lll}
\hline Feature & Pseudochylothorax & Chylothorax \\
\hline Triglycerides & & $>1.24 \mathrm{mmol} / \mathrm{l}(110 \mathrm{mg} / \mathrm{dll})$ \\
Cholesterol & $>5.18 \mathrm{mmol} / \mathrm{l}(200 \mathrm{mg} / \mathrm{dl})$ & Usually low \\
Cholesterol crystals & Often present & Absent \\
Chylomicrons & Absent & Usually present \\
\hline
\end{tabular}


Table 5 Other important causes of pleural effusions

\begin{tabular}{|c|c|c|c|}
\hline Condition & Clinical features & Pleural fluid characteristics & Special investigations and management \\
\hline Early post-CABG pleural effusion ${ }^{158}$ & $\begin{array}{l}\text { Occur within } 30 \text { days of } \mathrm{CABG} \text {. } \\
\text { Left }>\text { right. } \\
\text { Most small and asymptomatic. } \\
\text { Prevalence } 89 \% \text { at } 7 \text { days postoperatively }\end{array}$ & $\begin{array}{l}\text { Exudate. } \\
\text { Bloody (haematocrit }>5 \% \text { ). } \\
\text { Often eosinophilic }\end{array}$ & $\begin{array}{l}\text { Only perform diagnostic aspiration if the } \\
\text { patient is febrile, complains of pleuritic } \\
\text { chest pain or the effusion is very large. } \\
\text { Most settle spontaneously }\end{array}$ \\
\hline Late post-CABG pleural effusion ${ }^{159}$ & $\begin{array}{l}\text { Occur }>30 \text { days post-CABG. } \\
\text { Left }>\text { right. } \\
\text { May be large and associated with } \\
\text { dyspnoea }\end{array}$ & $\begin{array}{l}\text { Exudate. } \\
\text { Clear/yellow. } \\
\text { Lymphocytic }\end{array}$ & $\begin{array}{l}\text { Diagnostic aspiration to exclude other } \\
\text { causes and confirm the diagnosis. } \\
\text { Repeated therapeutic thoracentesis } \\
\text { usually successful for symptomatic } \\
\text { effusions. }\end{array}$ \\
\hline Urinothorax $^{160}$ & $\begin{array}{l}\text { Due to obstructive uropathy. } \\
\text { Urine tracks through the retroperitoneum } \\
\text { to the pleural space. }\end{array}$ & $\begin{array}{l}\text { Pleural fluid creatinine }>\text { serum } \\
\text { creatinine. } \\
\text { Transudate. } \\
\text { Low pH }\end{array}$ & $\begin{array}{l}\text { Usually resolves with relief of the renal } \\
\text { obstruction }\end{array}$ \\
\hline Ovarian hyperstimulation syndrome ${ }^{161}$ & $\begin{array}{l}\text { Life-threatening reaction to ovulation } \\
\text { induction (hCG or clomiphene). } \\
\text { May be pleural effusion alone (usually } \\
\text { right sided) or whole syndrome with: } \\
\text { massive ascites, renal and hepatic failure, } \\
\text { thromboemboli and ARDS }\end{array}$ & $\begin{array}{l}\text { Exudate with both protein and LDH in } \\
\text { exudative range }\end{array}$ & $\begin{array}{l}\text { Repeated therapeutic aspirations often } \\
\text { required to relieve dyspnoea }\end{array}$ \\
\hline Lymphoma-related pleural effusion ${ }^{162}$ & $\begin{array}{l}\text { Effusion may be associated with } \\
\text { mediastinal lymphadenopathy on CT but } \\
\text { often there are no clinical features to } \\
\text { distinguish from other causes of pleural } \\
\text { effusion }\end{array}$ & $\begin{array}{l}\text { Exudate. } \\
\text { Lymphocytic. } \\
\text { Positive cytology in around } 40 \% \text {. } \\
\text { Chylothorax in around } 15 \%\end{array}$ & $\begin{array}{l}\text { Pleural fluid flow cytometry and } \\
\text { cytogenetics may be useful. } \\
\text { Thoracoscopic pleural biopsies are often } \\
\text { negative but required to exclude other } \\
\text { causes if diagnosis unclear }\end{array}$ \\
\hline
\end{tabular}

ARDS, adult respiratory distress syndrome; CABG, coronary artery bypass graft; hCG, human chorionic gonadotrophin.

\section{Benign asbestos pleural effusion}

Benign asbestos pleural effusions are commonly diagnosed in the first two decades after asbestos exposure. The prevalence is dose-related with a shorter latency period than other asbestos-related disorders. ${ }^{155}$ The effusion is usually small and asymptomatic, often with pleural fluid which is haemorrhagic. ${ }^{156} 157$ There is a propensity for the effusion to resolve within 6 months, leaving behind residual diffuse pleural thickening. ${ }^{156} 157$ As there are no definitive tests, the diagnosis can only be made with certainty after a prolonged period of follow-up and consideration should be given to early thoracoscopy with pleural biopsy in any patient with a pleural effusion and a history of asbestos exposure, particularly in the presence of chest pain. Table 5 summarises clinical and pleural fluid characteristics of other important causes of unilateral pleural effusions.

\section{MANAGEMENT OF PERSISTENT UNDIAGNOSED EFFUSIONS}

Even after a complete investigation including thoracoscopic biopsies, a significant number of patients with pleural exudates are diagnosed with 'non-specific pleuritis' and no specific diagnosis can be made. A retrospective study of 75 such patients found that only $8.3 \%$ of these turned out to be malignant over a 2-year follow-up period. The majority of patients with non-specific pleuritis (91.7\%) followed a benign course, with spontaneous resolution of the effusion in $81.8 \%$ of cases. ${ }^{163}$

In patients not fit enough for thoracoscopy, it is sensible to reconsider diagnoses with a specific treatment (eg, TB, pulmonary embolism, lymphoma and chronic heart failure). A considerable number of undiagnosed pleural effusions in this category are due to a malignant process. Watchful waiting may be the appropriate management in this setting.

Competing interests No member of the Guideline Group is aware of any competing interests.

Provenance and peer review The draft guideline was available for online public consultation (July/August 2009) and presented to the BTS Winter Meeting (December 2009). Feedback was invited from a range of stakeholder institutions (see Introduction). The draft guideline was reviewed by the BTS Standards of Care Committee (September 2009).

\section{REFERENCES}

1. Sahn SA, Heffner JE. Pleural fluid analysis. In: Light RW, Lee YCG, eds. Textbook of pleural diseases. 2nd edn. London: Arnold Press, 2008:209-26. (4)

2. Yap $\mathbf{E}$, Anderson G, Donald J, et al. Pleural effusion in patients with pulmonary embolism. Respirology 2008;13:832-6. (3)

3. Porcel JM, Madronero AB, Pardina M, et al. Analysis of pleural effusions in acute pulmonary embolism: radiological and pleural fluid data from 230 patients. Respirology 2007:12:234-9. (3).

4. Blackmore CC, Black WC, Dallas RV, et al. Pleural fluid volume estimation: a chest radiograph prediction rule. Acad Radiol 1996;3:103-9. (2+).

5. Ruskin JA, Gurney JW, Thorsen MK, et al. Detection of pleural effusions on supine chest radiographs. AJR Am J Roentgenol 1987;148:681-3. (2+).

6. Armstrong $\mathbf{P}$, Wilson AG, Dee $\mathbf{P}$, et al. Imaging of diseases of the chest. 3rd edn New York: Mosby, 2001. (4).

7. Hirsch JH, Rogers JV, Mack LA. Real-time sonography of pleural opacities. AJR Am J Roentgenol 1981;136:297-301. (2-).

8. Kohan JM, Poe RH, Israel RH, et al. Value of chest ultrasonography versus decubitus roentgenology for thoracentesis. Am Rev Respir Dis 1986; 133:1124-6. (2+).

9. O'Moore PV, Mueller PR, Simeone JF, et al. Sonographic guidance in diagnostic and therapeutic interventions in the pleural space. AJR Am J Roentgenol 1987;149:1-5. (3).

10. Barnes TW, Morgenthaler TI, Olson EJ, et al. Sonographically guided thoracentesis and rate of pneumothorax. J Clin Ultrasound 2005;33:442-6. (3)

11. Grogan DR, Irwin RS, Channick R, et al. Complications associated with thoracentesis. A prospective randomized study comparing three different methods. Arch Intern Med 1990;150:873-7. (1+)

12. Raptopoulos V, Davis LM, Lee G, et al. Factors affecting the development of pneumothorax associated with thoracentesis. AJR Am J Roentgenol 1990;156:917-20. (3)

13. Lipscomb DJ, Flower CDR, Hadfield JW. Ultrsound of the pleura: an assessment of its clinical value. Clin Radiol 1981;32:289-90. (2+)

14. Wu RG, Yuan A, Liaw YS, et al. Image comparison of real-time gray-scale ultrasound and colour Doppler ultrasound for use in diagnosis of minimal pleural effusion. Am J Respir Crit Care Med 1994;150:510-14. (2+).

15. Roch A, Bojan M, Michelet $P$, et al. Usefulness of ultrasonography in predicting pleural effusions $>500 \mathrm{ml}$ in patients receiving mechanical ventilation. Chest 2005; 127:224-32. (2+)

16. Eibenberger $\mathbf{K L}$, Dock Wl, Ammann ME. Quantification of pleural effusions: sonography versus radiography. Radiology 1994;191:681-4. (2++).

17. Kearney SE, Davies CWH, Davies RJO. Computed tomography and ultrasound in parapneumonic effusions and empyema. Clin Radiol 2000;55:542-7. (3).

18. Görg CH, Restrepo I, Schwerk WB. Sonography of malignant pleural effusion. Eur Radiol 1997;7:1195-8. (3).

19. Yang PC, Luh KT, Chang D, et al. Value of sonography in determining the nature of pleural effusion: analysis of 320 cases. AJR Am J Roentgenol 1992;159:29-33. $(2++)$.

20. Qureshi NR, Rahman NM, Gleeson FV. Thoracic ultrasound in the diagnosis of malignant pleural effusion. Thorax 2009;64:139-43. $(2++)$. 
21. Diacon AH, Brutsche $\mathrm{MH}$, Soler M. Accuracy of pleural puncture sites. A prospective comparison of clinical examination with ultrasound. Chest 2003; 123:436-41. (2+).

22. Ferrer A, Osset J, Alegre J, et al. Prospective clinical and microbiological study of pleural effusions. Eur J Clin Microbiol Infect Dis 1999;18:237-41. (2+)

23. Abouzgheib W, Bartter $\mathrm{T}$, Dagher $\mathrm{H}$, et al. A prospective study of the volume of pleural fluid required for accurate diagnosis of malignant pleural effusion. Chest 2009; 135:999-1001. $(2++)$.

24. Swiderek J, Marcos S, Donthireddy V, et al. Prospective study to determine the volume of pleural fluid required to diagnose malignancy. Chest 2010;137:68-73. $(2++)$.

25. Manosca F, Schinstine M, Fetsch PA, et al. Diagnostic effects of prolonged storage on fresh effusion samples. Diagn Cytopathol 2007;35:7-11. (2+).

26. Sahn S. Pleural fluid analysis: narrowing the differential diagnosis. Semin Respir Med 1987:9:22-9. (4).

27. Villena V, Lopez-Encuentra A, Garcia-Lujan R, et al. Clinical implications of appearance of pleural fluid at thoracentesis. Chest 2004:125:156-9. (3).

28. Light RW, Erozan YS, Ball WCJ. Cells in pleural fluid. Their value in differential diagnosis. Arch Intern Med 1973;132:854-60. (3).

29. Ali HA, Lippmann M, Mundathaje U, et al. Spontaneous hemothorax. Chest 2008;134:1056-65. (4).

30. Light RW, MacGreggor I, Luchsinger PC, et al. Pleural effusions: the diagnostic separation of transudates and exudates. Ann Intern Med 1972;77:507-13. (2++).

31. Heffner JE, Brown LK, Barbieri CA, et al. Diagnostic value of tests that discriminate between exudative and transudative pleural effusions. Chest 1997;111:970-80. (1+).

32. Romero-Candiera S, Romero-Brufao S, Fernandez C, et al. Is it meaningful to use biochemical parameters to discriminate between transudative and exudative pleural effusions? Chest 2002;122:1524-9. (2++)

33. Romero-Candiera S, Fernandez C, Martin C, et al. Influence of diuretics on the concentration of proteins and other components of pleural transudates in patients with heart failure. Am J Med 2001;110:681-6. (3).

34. Gotsman I, Fridlender Z, Meirovitz A, et al. The evaluation of pleural effusions in patients with heart failure. Am J Med 2001;111:375-8. (3)

35. Porcel JM, Pena JM, Vicente de Vera C. Bayesian analysis using continuous likelihood ratios for identifying pleural exudates. Respir Med 2006;100:1960-5. $(2-)$.

36. Liao H, Na MJ, Dikensoy 0, et al. Diagnostic value of pleural fluid N-terminal pro-brain natriuretic peptide levels in patients with cardiovascular diseases. Respirology 2008;13,53-7. (2-).

37. Kolditz M, Halank M, Schiemanck CS, et al. High diagnostic accuracy of NT-proBNP for cardiac origin of pleural effusions. Eur Respir J 2006;28:144-150. $(2++)$.

38. Porcel JM, Chorda J, Cao G, et al. Comparing serum and pleural fluid pro-brain natriuretic peptide (NT- proBNP) levels with pleural-to-serum albumin gradient for the identification of cardiac effusions misclassified by Light's criteria. Respirology 2007; 12:654-9. $(\mathbf{2}++$

39. Gegenhuber A, Mueller T, Dieplinger B, et al. Plasma B-type Natriuretic peptide in patients with pleural effusions. Chest 2005:128:1003-9. (2++)

40. Tomcsanyi J, Nagy E, Somloi M, et al. NT-brain natriuretic peptide levels in pleural fluid distinguish between pleural transudates and exudates. Eur J Heart Fail 2004:6:753-6. $(2++)$

41. Porcel JM, Vives M, Cao G, et al. Measurement of Pro-Brain Natriuretic peptide in pleural fluid for the diagnosis of pleural effusions due to heart failure. Am J Med 2004:116:117-20. (2-).

42. Hann CH, Choi JE, Chung JH. Clinical utility of pleural fluid NT-pro Brain Natriuretic peptide (NT-proBNP) in patients with pleural effusions. Intern Med 2008:47:1669-74. $(2++)$.

43. Pettersson T, Riska H. Diagnostic value of total and differential leukocyte counts in pleural effusions. Acta Med Scand 1981:210:129-35. (3)

44. Ansari T, Idell S. Management of undiagnosed persistent pleural effusions. Clin Chest Med 1998:19:407-17. (4)

45. Light RW. Pleural diseases, 3rd edn. Baltimore: Williams and Wilkins, 1995. (3).

46. Özkara SK, Turan G, Basyigit I. Clinicopathologic significance of eosinophilic pleural effusions in a population with a high prevalence of tuberculosis and cancer. Acta Cytol 2007;51:773-81. (3)

47. Adelman $\mathbf{M}$, Albelda SM, Gottlieb J, et al. Diagnostic utility of pleural fluid eosinophilia. Am J Med 1984:77:915-20. (3)

48. Wysenbeek AJ, Lahav M, Aelion JA, et al. Eosinophilic pleural effusion: a review of 36 cases. Respiration 1985;48:73-6. (3)

49. Martinez-Garcia MA, Cases-Viedma E, Cordero-Rodriguez PJ, et al. Diagnostic utility of eosinophils in the pleural fluid. Eur Respir $J$ 1999;15:166-9. (3)

50. Good JT Jr, Taryle DA, Maulitz RM, et al. The diagnostic value of pleural fluid pH. Chest 1980;78:55-9. (3).

51. Potts DE, Taryle A, Sahn SA. The glucose-pH relationship in parapneumonic effusions. Arch Intern Med 1978:138:1378-80. (3).

52. Sahn SA, Good JTJ. Pleural fluid pH in malignant effusions. Diagnostic, prognostic, and therapeutic implications. Ann Intern Med 1988:108:345-9. (2++).

53. Heffner JE, Nietert PJ, Barbieri C. Pleural fluid $\mathrm{pH}$ as a predictor of survival for patients with malignant pleural effusions. Chest 2000;117:79-86. (1+).
54. Heffner JE, Brown LK, Barbieri C, et al. Pleural fluid chemical analysis in parapneumonic effusions. A meta-analysis. Am J Respir Crit Care Med 1995:151:1700-8. (1+).

55. Maskell NA, Gleeson FV, Darby M, et al. Diagnostically significant variations in pleural fluid $\mathrm{pH}$ in loculated parapneumonic effusions. Chest 2004;126:2022-4. (3).

56. Rahman NM, Mishra EK, Davies HE, et al. Clinically important factors influencing the diagnostic measurement of pleural fluid $\mathrm{pH}$ and glucose. Am J Respir Crit Care Med 2008;178:483-90. $(2++)$.

57. Emil P, Lesho DO, Bernard J, et al. Is pH paper an acceptable low cost alternative to the blood gas analyser for determining pleural fluid $\mathrm{pH}$ ? Chest 1997; 112:1291-92. $(2+)$.

58. Light RW, Ball WC. Glucose and amylase in pleural effusions. JAMA 1973;225:257-60. (3)

59. Sahn SA. Pathogenesis and clinical features of diseases associated with low pleural fluid glucose. In: Chretien J, Bignon J, Hirsch A, eds. The pleural in health and disease. New York: Marcel Dekker, 1985:267-85. (4)

60. Sahn SA. The pleura. Am Rev Respir Dis 1988;138:184-234. (4).

61. Joseph J, Viney S, Beck P, et al. A prospective study of amylase-rich pleural effusions with special reference to amylase isoenzyme analysis. Chest 1992:102:1455-9. (3)

62. Sherr HP, Light RW, Merson MH, et al. Origin of pleural fluid amylase in oesophageal rupture. Ann Intern Med 1972;76:985-6. (4)

63. Kramer M. High amylase levels in neoplasm related pleural effusion. Ann Intern Med 1989;110:567-9. (4)

64. Branca P, Rodriguez M, Rogers JT, et al. Routine measurement of pleural fluid amylase is not indicated. Arch Intern Med 2001;161:228-32. (3)

65. Lankisch PG, Droge M, Becher R, et al. Pleural effusions: a new negative prognostic parameter for acute pancreatitis. Am J Gastroenterol 1994; 89:1848-51. (3)

66. Inglesias JI, Cobb J, Levey J, et al. Recurrent left pleural effusion in a 44-year-old woman with a history of alcohol abuse. Chest 1996:110:547-49. (3).

67. Salyer WR, Eggleston JC, Erozan YS. Efficacy of pleural needle biopsy and pleura fluid cytopathology in the diagnosis of malignant neoplasm involving the pleura. Chest 1975:67:536-9. (4)

68. Nance KV, Shermer RW, Askin FB. Diagnostic efficacy of pleural biopsy as compared with that of pleural fluid examination. Mod Pathol 1991;4:320-4. (2-)

69. Prakash UB, Reiman HM. Comparison of needle biopsy with cytologic analysis for the evaluation of pleural effusion: analysis of 414 cases. Mayo Clin Proc 1985:60:158-64. (2-)

70. Garcia L. The value of multiple fluid specimens in the cytological diqgnosis of malignancy. Mod Pathol 1994;7:665-8. (3)

71. Dekker A, Bupp PA. Cytology of serous effusions. An investigation into the usefulness of cell blocks versus smears. Am J Clin Pathol 1978;70:855-60. (3).

72. Chandra A, Cross P, Denton K, et al. The BSCC code of practice: exfoliative cytolopathology (excluding gynaecological cytopathology). Cytopathology 2009;20:211-33. (4).

73. Denton K, Giles T, Smith $\mathrm{P}$, et al. Tissue pathways for exfoliative cytology and fine needle aspiration cytology. London: Royal College of Pathologists, 2009. (4).

74. Porcel M, Vives M, Esquerda A, et al. Use of a panel of tumour markers (carcinoembryonic antigen, cancer antigen 125, carbohydrate antigen 15-3 and cytokeratin 19 fragments) in pleural fluid for the differential diagnosis of benign and malignant effusions. Chest 2004;126:1757-63. (2+).

75. Sherpereel A, Grigoriu B, Conti M, et al. Soluble mesothelin-related peptides in the diagnosis of malignant pleural mesothelioma. Am J Respir Crit Care Med 2006;173:1155-60. (2+)

76. Creaney J, Yeoman D, Naumoff L, et al. Soluble mesothelin in effusions: a useful tool for the diagnosis of malignant mesothelioma. Thorax 2007:62:569-76. $(2++)$.

77. Creaney J, Van Bruggen I, Segal A, et al. Combined CA125 and mesothelin levels for the diagnosis of malignant mesothelioma. Chest 2007:132:1239-46. (2+).

78. Cristaudo A, Foddis R, Vivaldi A, et al. Clinical significance of serum mesothelin in patients with mesothelioma and lung cancer. Clin Cancer Res 2007;13:5076-81. $(2+)$.

79. Robinson B, Creaney J, Lake R, et al. Mesothelin-family proteins and diagnosis of mesothelioma. Lancet 2003;362:1612-16. (2+).

80. Davies HE, Sadler RS, Bielsa $\mathrm{S}$, et al. The clinical impact and reliability of pleura fluid mesothelin in undiagnosed pleural effusions. Am J Respir Crit Care Med 2009:180:437-44. (2+)

81. Hassan R, Remaley A, Sampson M, et al. Detection and quantitation of serum mesothelin, a tumour marker for patients with mesothelioma and ovarian cancer Clin Cancer Res 2006:12:447-53. (2-).

82. Traill ZC, Davies RJO, Gleeson FV. Thoracic computed tomography in patients with suspected malignant pleural effusions. Clin Radiol 2001:56:193-6. (2++).

83. Mcloud T, Flower C. Imaging of the pleura: sonography, CT, and MR imaging AJR Am J Roentgenol 1991;156:1145-53. (4).

84. Waite RJ, Carbonneau RJ, Balikian JP, et al. Parietal pleural changes in empyema: appearances on CT. Radiology 1990:175:145-50. (3)

85. Leung AN, Muller NL, Miller RR. CT in differential diagnosis of diffuse pleural disease. AJR Am J Roentgenol 1989:154:487-92. (2-).

86. Scott EM, Marshall TJ, Flower CDR, et al. Diffuse pleural thickening: percutaneous CT-guided cutting needle biopsy. Radiology 1995;194:867-70. (2+). 
87. Falaschi F, Battolla L, Mascalchi $\mathrm{M}$, et al. Usefulness of MR signal intensity in distinguishing benign from malignant pleural disease. AJR Am J Roentgenol 1995; 166:963-8. $(\mathbf{2 +})$

88. Knuuttila A, Kivisaari L, Kivisaari A, et al. Evaluation of pleural disease using MR and CT. Acta Radiol 2001;42:502-7. (2+).

89. Geisel FL, Bischoff H, Von Tengg-Kobligk H, et al. Dynamic contrast enhanced MRI of malignant pleural mesothelioma: a feasibility study of non-invasive assessment, therapeutic follow-up, and possible predictor of improved outcome. Chest 2006:129:1570-6. (2+).

90. Duysinx B, Nguyen D, Louis $\mathrm{R}$, et al. Evaluation of pleural disease with 18-Fluorodeoxyglucose positron emission tomography imaging. Chest 2004;125:489-93. $(2++)$.

91. Bury TH, Paulus P, Dowlati A, et al. Evaluation of pleural disease with FDG-PET imaging: preliminary report. Thorax 1997:52:187-9. $(\mathbf{2 + + 1}$

92. Kwek BH, Aquino SL, Fischman J. Fluorodeoxyglucose positron emission tomography and CT after talc pleurodesis. Chest 2004;125:2356-60. (3)

93. Steinert HC, Dellea MMS, Burger $C$, et al. Therapy response evauation in malignant pleural mesothelioma with integrated PET-CT imaging. Lung Cancer 2005;49(Suppl 1):S33-5. (2+).

94. Ceresoli GL, Chiti A, Zucali PA, et al. Early response evaluation in malignant pleural mesothelioma by positron emission tomography with 18F-fluorodeoxyglucose. J Clin Oncol 2006;24:4587-93. $(2++)$

95. Francis RJ, Byrne MJ, Van der Schaaf AA, et al. Early prediction of response to chemotherapy and survival in malignant pleural mesothelioma using a novel semiautomated 3-dimensional volume-based analysis of serial ${ }^{18} \mathrm{~F}-\mathrm{FDG}$ PET scans. J Nucl Med 2007:48:1449-58. (2++).

96. Tomlinson JR. Invasive procedures in the diagnosis of pleural disease. Semin Respir Med 1987:9:30-60. (2+)

97. Adams RF, Gleeson FV. Percutaneous image-guided cutting needle biopsy of the pleura in the diagnosis of malignant mesothelioma. Chest 2001;120:1798-802. (2-).

98. Adams RF, Gleeson FV. Percutaneous image-guided cutting-needle biopsy of the pleura in the presence of a suspected malignant effusion. Radiology 2001;219:510-14. (2+).

99. Maskell NA, Gleeson FV, Davies RJO. Standard pleural biopsy versus CT guided cutting-needle biopsy for the diagnosis of malignant disease in pleural effusions: a randomised controlled trial. Lancet 2003:361:1326-31. (1++).

100. Diacon $\mathbf{A H}$, Van de Wal BW, Wyser $\mathrm{C}$, et al. Diagnostic tools in tuberculous pleurisy: a direct comparative study. Eur Respir J 2003;22:589-91. (2++).

101. Blanc FX, Atassi $\mathrm{K}$, Bignon J, et al. Diagnostic value of medical thoracoscopy in pleural disease: a 6-year retrospective study. Chest 2002;121:1677-83. (2-).

102. Boutin C, Rey F. Thoracoscopy in pleural malignant mesothelioma: a prospective study of 188 consecutive patients. Part 1: Diagnosis. Cancer 1993;72:389-93.(2+).

103. Hansen M, Faurschou P, Clementsen P. Medical thoracoscopy, results and complications in 146 patients: a retrospective study. Respir Med 1998:92:228-32. (2-)

104. Menzies R, Charbonneau M. Thoracoscopy for the diagnosis of pleural disease. Ann Intern Med 1991:114:271-6. (2+).

105. Davidson AC, George RJ, Sheldon CD, et al. Thoracoscopy: assessment of a physician service and comparison of a flexible bronchoscope used as a thoracoscope with a rigid thoracoscope. Thorax 1988:43:327-32. (3)

106. Debeljak A, Kecelj P. Medical thoracoscopy: wxperience with 212 patients J BUON 2000;5:169-72. (2-).

107. Fielding D, Hopkins P, Serisier D. Frozen section of pleural biopsies at medical thoracoscopy assists in correctly identifying benign disease. Respirology 2005; 10:636-42. (3).

108. Fletcher SV, Clark RJ. The Portsmouth thoracoscopy experience, an evaluation of service by retrospective case note analysis. Respir Med 2007;101:1021-5. (3).

109. Janssen JP, Boutin C. Extended thoracoscopy: a biopsy method to be used in case of pleural adhesions. Eur Respir J 1992:5:763-6. (3)

110. Lee P, Hsu A, Lo C, et al. Prospective evaluation of flex-rigid pleuroscopy for indeterminate pleural effusion: accuracy, safety and outcome. Respirology 2007; 12:881-6. (2-).

111. Macha HN, Reichle G, von ZD, et al. The role of ultrasound assisted thoracoscopy in the diagnosis of pleural disease. Clinical experience in 687 cases. Eur $J$ Cardiothorac Surg 1993; 7:19-22. (3)

112. McLean AN, Bicknell SR, McAlpine LG, et al. Investigation of pleural effusion: an evaluation of the new Olympus LTF semiflexible thoracofiberscope and comparison with Abram's needle biopsy. Chest 1998;114:150-3. (2-).

113. Munavvar M, Khan MA, Edwards J, et al. The autoclavable semirigid thoracoscope: the way forward in pleural disease? Eur Respir $J$ 2007;29:571-4. (2-).

114. Oldenburg FA Jr, Newhouse MT. Thoracoscopy. A safe, accurate diagnostic procedure using the rigid thoracoscope and local anesthesia. Chest 1979;75:45-50. (2-).

115. Sakuraba M, Masuda K, Hebisawa A, et al. Diagnostic value of thoracoscopic pleural biopsy for pleurisy under local anaesthesia. Aust NZ J Surg 2006;76:722-4. (2-).

116. Schwarz C, Lubbert H, Rahn W, et al. Medical thoracoscopy: hormone receptor content in pleural metastases due to breast cancer. Eur Respir $J$ 2004:24:728-30. (3).

117. Simpson G. Medical thoracoscopy in an Australian regional hospital. Intern Med J 2007;37:267-9. (2-).
118. Smit HJ, Schramel FM, Sutedja TG, et al. Video-assisted thoracoscopy is feasible under local anesthesia. Diagn Ther Endosc 1998;4:177-82. (3)

119. Tassi G, Marchetti G. Minithoracoscopy: a less invasive approach to thoracoscopy Chest 2003:124:1975-7. (3)

120. Wilsher ML, Veale AG. Medical thoracoscopy in the diagnosis of unexplained pleural effusion. Respirology 1998;3:77-80. (2-).

121. Janssen JP, Ramlal $S$. The long term follow up of exudative pleural effusion afte nondiagnostic thoracoscopy. J Bronchol 2004;11:169-74. (2-).

122. Viskum K, Enk B. Complications of thoracoscopy. Poumon Coeur 1981;37:25-8. (3)

123. Heaton RW, Roberts CM. The role of fibreoptic bronchoscopy in the investigation of pleural effusion. Postgrad Med J 1988;64:581-2. (3)

124. Upham JW, Mitchell CA, Armstrong JG, et al. Investigation of pleural effusion: the role of bronchoscopy. Aust NZ J Med 1992;22:41-3. (3).

125. Feinsilver SH, Barrows AA, Braman SS. Fiberoptic bronchoscopy and pleural effusion of unknown origin. Chest 1986;90:516-19. (3).

126. Chang SC, Perng RP. The role of fiberoptic bronchoscopy in evaluating the causes of pleural effusions. Arch Intern Med 1989:149:855-7. (2+).

127. Bueno EC, Clemente GM, Castro CB, et al. Cytology and bacteriologic analysis of fluid and pleural biopsy specimens with Cope's needle. Study of 414 patients. Arch Intern Med 1990:150:1190-4. (2+).

128. Liang $\mathbf{Q L}$, Shi HZ, Wang K, et al. Diagnostic accuracy of adenosine deaminase in tuberculous pleurisy: a meta-analysis. Respir Med 2008;102:744-54. (1+).

129. Zemlin AE, Burgess LJ, Carstens ME, et al. The diagnostic utility of adenosine deaminase isoenzymes in tuberculous pleural effusions. Int J Tuberc Lung Dis 2009;13:214-20. (2-).

130. Antonangelo L, Vargas FS, Almeida LP, et al. Influence of storage time and temperature on pleural fluid adenosine deaminase determination. Respirology 2006:11:488-92. (3).

131. Greco S, Girardi E, Masciangelo R, et al. Adenosine deaminase and interferon gamma measurements for the diagnosis of tuberculous pleurisy: a meta-analysis. Int J Tuberc Lung Dis 2003:7:777-86. (1+)

132. Losi M, Bossink A, Codecasa $L$, et al. Use of a T-cell interferon-gamma release assay for the diagnosis of tuberculous pleurisy. Eur Respir $\mathrm{J}$ 2007:30:1173-9. $(2++)$.

133. Ariga $\mathbf{H}$, Kawabe $Y$, Nagai $\mathrm{H}$, et al. Diagnosis of active tuberculous serositis by antigen-specific interferon-gamma response of cavity fluid cells. Clin Infect Dis 2007:45:1559-67. $(2++)$

134. Trajman A, Pai M, Dheda K, et al. Novel tests for diagnosing tuberculous pleural effusion: what works and what does not? Eur Respir $J$ 2008;31:1098-106. (4).

135. Baumann MH, Nolan R, Petrini M, et al. Pleural tuberculosis in the United States: incidence and drug resistance. Chest 2007;131:1125-32. (3).

136. Horler A. The pleural and pulmonary complications of rheumatoid arthritis Ann Intern Med 1959;51:1179-203. (4)

137. Balbir-Gurman A, Yigla M, Mahir AM. Rheumatoid pleural effusion. Semin Arthritis Rheum 2006;35:368-78. (4)

138. Ferguson GC. Cholesterol pleural effusion in rheumatoid lung disease. Thorax 1966;21:577-82. (3, 4)

139. Lillington GA, Carr DT, Mayne JG. Rheumatoid pleurisy with effusion. Arch Intern Med 1971;128:764-8. (3)

140. Hunder GG, McDuffie FC, Huston KA, et al. Pleural fluid complement, complement conversion, and immune complexes in immunologic and non immunologic diseases. J Lab Clin Med 1977;90:971-80. (3)

141. Pettersson T, Klockars M, Hellstrom PE. Chemical and immunological features of pleural effusions: comparison between rheumatoid arthritis and other diseases. Thorax 1982;37:354-61. (2+).

142. Halla JT, Schronhenloher RE, Volanakis JE. Immune complexes and other laboratory features of pleural effusions. Ann Intern Med 1980;92:748-52. (3).

143. Hunninghake GW, Fauci AS. Pulmonary involvement in the collagen vascular diseases. Am Rev Respir Dis 1979;119:471-85. (4)

144. Good JT Jr, King TE, Antony VB, et al. Lupus pleuritis. Clinical features and pleural fluid characteristics with special reference to pleural fluid antinuclear antibodies. Chest 1983;84:714-18. (4)

145. Carr DT. Pleural fluid glucose in systemic lupus erythematosus. Mayo Clin Proc 1970;45:409-12. (3).

146. Wang DY, Yang PC, Yu WL, et al. Serial antinuclear antibodies titre in pleural and pericardial fluid. Eur Respir J 2000:15:1106-10. (2+).

147. Porcel JM, Orid-Ros J, Esquerda A, et al. Antinuclear antibody testing in pleura fluid for the diagnosis of lupus pleuritis. Lupus 2007:16:25-7. (2-).

148. Stein PD, Terrin ML, Hales CA, et al. Clinical, laboratory, roentgenographic, and electrocardiographic findings in patients with acute pulmonary embolism and no pre-existing cardiac or pulmonary disease. Chest 1991;100:598-603. (3)

149. Romero Candeira S, Hernandez Blasco L, Soler MJ, et al. Biochemical and cytological characteristics of pleural effusions secondary to pulmonary embolism. Chest 2002;121:465-9. (3)

150. Doerr CH, Allen MS, Nichols FC, et al. Etiology of chylothorax in 203 patients. Mayo Clin Proc 2005;80:867-70. (3)

151. Hillerdal G. Chyliform(cholesterol) pleural effusion. Chest 1985;88:426-8. (4)

152. Hillerdal G. Chylothorax and pseudochylothorax. Eur Respir J 1997 10:1150-6. (4)

153. Wrightson JM, Stanton AE, Maskell NA, et al. Pseudochylothorax without pleural thickening-time to reconsider pathogenesis? Chest 2009;136:1144-7. (3). 
154. Staats BA, Ellefson RD, Budahn LL, et al. The lipoprotein profile of chylous and non-chylous pleural effusions. Mayo Clin Proc

1980;55:700-4. (3)

155. Epler GR, McLoud TC, Gaensler EA. Prevalence and incidence of benign asbestos pleural effusion in a working population. JAMA 1982;247:617-22 (3).

156. Hillerdal G, Ozesmi M. Benign asbestos pleural effusion: 73 exudates in 60 patients. Eur J Respir Dis 1987;71:113-21. (3).

157. Robinson BW, Musk AW. Benign asbestos pleural effusion: diagnosis and course. Thorax 1981;36:896-900. (4)

158. Light RW. Pleural effusions following cardiac injury and coronary artery bypass graft surgery. Semin Respir Crit Care Med 2001;22:657-64. (4).
159. Light R, Rogers J, Moyers J, et al. Prevalence and clinical course of pleural effusions at 30 days after coronary artery and cardiac surgery. Am J Respir Crit Care Med 2002;166:1567-71. (3)

160. Garcia-Pachon E, Padilla-Navas I. Urinothorax: case report and review of the literature with emphasis on biochemical diagnosis. Respiration 2004;71:533-6. (4)

161. Delvigne A, Rosenburg $S$. Review of clinical course and treatment of ovarian hyperstimulation syndrome (OHSS). Hum Reprod Update 2003:9:77-96. (3)

162. Ceyhan BB, Demiralp E, Celikel T. Analysis of pleural effusions using flow cytometry. Respiration 1996;63:17-24. (2+).

163. Venekamp LN, Velkeniers B, Noppen M. Does 'idiopathic pleuritis' exist? Natura history of non-specific pleuritis diagnosed after thoracoscopy. Respiration 2005:72:74-8. (3) 